\title{
Genetic tendency in Crohn's disease
}

\author{
I. G. HISLOP AND A. KERR GRANT \\ From the Gastroenterology Unit, The Queen Elizabeth Hospital, Woodville, South Australia
}

SUMmaRY A fifth instance of Crohn's disease in identical twins is reported. The evidence for genetic expression of the disease is considered and the possible mechanisms involved are reviewed.

The familial incidence of regional enteritis has been recently emphasized (Steigman and Shapiro, 1961; Kirsner and Spencer, 1963; Sherlock, Bell, Steinberg, and Almy, 1963), but whether the dominant influence in the development of the disease is exerted by genetic or by environmental factors remains unsettled.

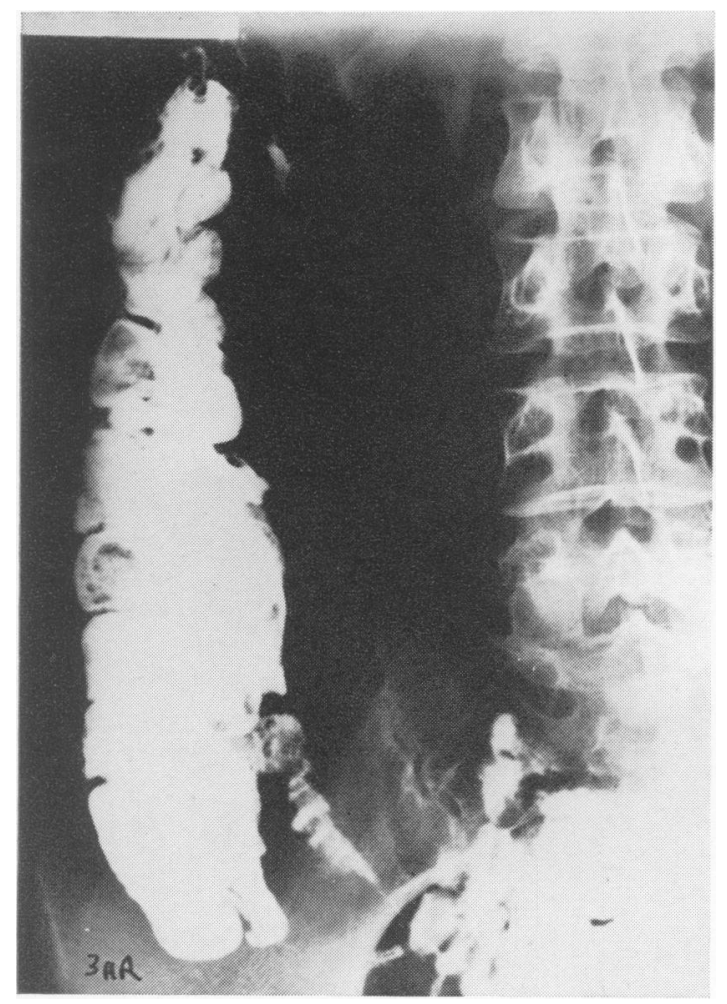

FIG. 1. A follow-through barium meal examination in the younger twin showing the narrowed segment of terminal ileum.
This paper reviews some of the genetic aspects with particular reference to the occurrence of Crohn's disease in monozygotic twins, and adds another such instance to the literature.

\section{CLINICAL RECORD}

The elder sister, a 27-year-old housewife, in May 1963, began to suffer pain in the right iliac fossa. These bouts continued for two years at which time she developed an acute intestinal obstruction. At laparotomy 18 inches of thickened and obstructed terminal ileum was found and resected, and an ileocolic anastomosis performed. The histology of the affected bowel was consistent with a diagnosis of regional ileitis. Apart from persistent diarrhoea, recently controlled by cholestyramine therapy, the patient has remained in good health over a four-year follow-up period. Tests of intestinal absorption and radiological studies have shown no recurrence of the disease. The identical twin, also a housewife, in April 1964, underwent laparotomy for suspected acute appendicitis. The terminal ileum was noted to be oedematous and inflamed, and the appendix, which was described as normal, was excised. She remained well until 1966 when, in the third month of her first pregnancy, she developed pain in the right iliac fossa. The episode lasted 10 days and subsided without therapy. Radiological examination of the small bowel revealed a narrowed terminal ileum (Fig. 1). In November 1968, when five months pregnant with her second child, she developed a recurrence of abdominal pain associated with vomiting and diarrhoea. An abdominal radiograph revealed multiple fluid levels in the small bowel. The bowel obstruction was treated by conservative methods and she was started on prednisolone in a dose of $60 \mathrm{mg}$ daily. This therapy was gradually reduced until a maintenance dose of $10 \mathrm{mg}$ daily was established. During the remainder of her gestation period she suffered only occasional mild bouts of diarrhoea and abdominal pain, finally delivering a normal male infant.

\section{DISCUSSION}

Crohn's disease in monozygotic twins has been reported in three previous instances and reference 
has been made to a fourth occurrence. Edwards (1954) described identical female twins who underwent surgery aged 27 and 30 years respectively. The operative findings of regional ileitis were said to be identical in each except that one had a fistula. Both were treated by bowel resection and regained full health. Freysz, Haemmerli, and Kartagener (1958) reported its occurrence in female twins of Jewish race. One twin had an ileocaecal resection aged 59 years, while the other, at the age of 63 , had a laparotomy for supposed acute appendicitis. A third set of female twins (Niederle and Sebek, 1960) developed the disease when both were aged 47 years. The operation findings of typical regional enteritis were found to be similar in each patient. Sherlock et al (1963) quote Janowitz as having found Crohn's disease in male twins aged 44 years. The father was also noted to have symptoms consistent with a diagnosis of the disease, but he refused further investigation.

The most extensive review on the familial aspects of regional enteritis are those of Sherlock et al (1963) and Almy and Sherlock (1966). The frequency of the occurrence of the disease within family groups and the variety of combinations of the affected members led them to discuss the genetic mechanisms which might be involved. Its association with spondylitis, which is transmitted by an autosomal dominant gene, has lent further support to the concept of a genetic factor (Acheson, 1960a), while the increased incidence of Crohn's disease in the Jewish population has also been considered to indicate a genetic predisposition (Acheson, 1960b).

Development of the disease in monozygotic twins provides a unique opportunity to study the natural history of the disease in two similar genetic environments. It is notable that five cases of concordance in such twins have been reported, while Almy and Sherlock cite only one instance of discordance (only one twin being affected by the disease). They were also able to find only two sets of dizygotic twins with the disease. In each of the five examples of regional enteritis in identical twins the markedly similar clinical presentation has been apparent. The greatest disparity in time between diagnoses in any one set of twins was four years; in two instances the diagnosis was reached while both twins were of similar age, while the time difference in our set was only 11 months. In each pair there has been a close parallelism in the site, extent, and progress of the disease, although in two sets, including our own, only one twin required bowel resection. However, this remarkable approximation in the course of the disease in both twins of each pair strongly supports the concept of a genetic mechanism being responsible for the development of the disease in some cases.

Reports of multiple cases in sibships, in collateral relatives, and in different generations of the same family (Kirsner and Spencer, 1963) also suggest such an explanation.

We would agree with Almy and Sherlock's contention that the transmission of the disease may be due to a dominant gene with reduced pent trance, but their suggestion of a multigene focus or possibly a genetic predisposition requiring an environmental factor for its clinical expression would seem more likely.

\section{REFERENCES}

Acheson, E. D. (1960a). An association between ulcerative colitis, regional enteritis and ankylosing spondylitis. Quart. J. Med., 29, 489-499.

(1960b). The distribution of ulcerative colitis and regional enteritis in United States veterans with particular reference to the Jewish religion. Gut, 1, 291-293.

Almy, T. P., and Sherlock, P. (1966). Genetic aspects of ulcerative colitis and regional enteritis. Gastroenterology, 51, 757-763.

Edwards, H. C. (1954). Recent Advances in Surgery, 4th ed. Churchill, London.

Freysz, H., Haemmerli, A., and Kartagener, M. (1958). Ileitis regionalis bei einem weiblichen Zwillingspaar. Gastroenterologia (Basle), 89, 75-82.

Kirsner, J. B., and Spencer, J. A. (1963). Familial occurrences of ulcerative colitis, regional enteritis and ileocolitis. Ann. intern. Med., 59, 133-144.

Niederle, B., and Sebek, V. (1960). Terminal ileitis in monozygotic twins (Czech). Čas. Lék čes., 99, 1038-1044.

Sherlock, P., Bell, B. M., Steinberg, H., and Almy, T. P. (1963). Familial occurrence of regional enteritis and ulcerative colitis. Gastroenterology, 45, 413-420.

Steigman, F., and Shapiro, S. (1961). Familial regional enteritis. Ibid, 40, 215-218. 